\title{
Permissive Sites and Topology of an Outer Membrane Protein with a Reporter Epitope
}

\author{
ALAIN CHARBIT, JORGE RONCO, VALÉRIE MICHEL, CATHERINE WERTS, \\ AND MAURICE HOFNUNG* \\ Unité de Programmation Moléculaire et Toxicologie Génétique, CNRS UA 271, INSERM U163, \\ Institut Pasteur, 25 rue du Dr. Roux, 75015 Paris, France
}

Received 30 May 1990/Accepted 6 October 1990

\begin{abstract}
We are developing a genetic approach to study with a single antibody the folding and topology of LamB, an integral outer membrane protein from Escherichia coli K-12. This approach consists of inserting the same reporter foreign antigenic determinant (the $\mathrm{C} 3$ epitope from poliovirus) at different sites of LamB so that the resulting hybrid proteins have essentially kept the in vivo biological properties of LamB and therefore its cellular location and structure; the corresponding sites are called permissive sites. A specific monoclonal antibody can then be used to examine the position of the reporter epitope with respect to the protein and the membrane. We present an improved and efficient procedure that led us to identify eight new permissive sites in LamB. These sites appear to be distributed on both sides of the membrane. At one of them (after residue 253), the C3 epitope was detected on intact bacteria, providing the first direct argument for exposure of the corresponding LamB region at the cell surface. At this site as well as at four others (after residues 183, 219, 236, and 352), the $\mathrm{C3}$ epitope could be detected with the $\mathrm{C3}$ monoclonal antibody at the surface of the extracted trimeric LamB-C3 hybrid proteins. We provide a number of convergent arguments showing that the hybrid proteins are not strongly distorted with respect to the wild-type protein so that the conclusions drawn are also valid for this protein. These conclusions are essentially in agreement with the proposed folding model for the LamB protein. They agree, in particular, with the idea that regions 183 and 352 are exposed to the periplasm. In addition, they suggest that region 236 is buried at the external face of the outer membrane and that region 219 is exposed to the periplasm. Including the 3 sites previously determined, 11 permissive sites are now available in LamB, including 3 at the cell surface and most probably at least 3 in the periplasm. We discuss the nature of such sites, the generalization of this approach to other proteins, and possible applications.
\end{abstract}

Genetic fusions between proteins have proved to be useful tools in the study of a large number of biological problems. $\beta$-Galactosidase, alkaline phosphatase, and $\beta$-lactamase have been used as reporter enzymes to study the location or the folding of proteins and for various biotechnological applications (for recent discussions, see references 7, 27, and 28). For topological studies, such fusions present at least two kinds of limitations. First, they usually delete the $\mathrm{COOH}$-terminal end of the vehicle protein; this end can be critical for the normal biogenesis of the protein. Second, properties of the passenger enzyme (size, sequence, etc.) may alter the location or folding of the vehicle protein (see, for example, references 31 and 42). These two problems occur in the case of the outer membrane protein $\operatorname{LamB}(3,4)$, which is why the topological information on this protein comes from other approaches $(10,21)$.

LamB is representative of a class of integral membrane proteins, the porins (35), which are peculiar for at least two reasons. They are mostly hydrophilic, with no apparent hydrophobic transmembrane segment, and the structured regions are essentially composed of beta-strand segments. LamB plays a role in the penetration of maltose and maltodextrins through the outer membrane and is the cell surface receptor for a number of bacteriophages, including phage lambda; the active form is a trimer (reference 10 and references therein). In the absence of precise crystallo-

\footnotetext{
* Corresponding author.
}

graphic data, most of our knowledge of LamB organization relies on genetic, immunological, and biochemical data. On these bases, we have proposed a two-dimensional folding model that we would like to test and refine $(9,10)$.

To circumvent the problems encountered with reporter enzymes, we started a new and complementary approach that consists of using as a reporter a small peptide corresponding to a foreign antigenic determinant (i.e., a reporter epitope) which we insert genetically into permissive sites of LamB (4, 8; reviewed in reference 22). Such sites tolerate insertions without loss of most biological properties of the protein and therefore without major changes in its cellular location and structure. Permissive sites can be identified by a genetic method (8), and the hybrid proteins generated are then probed with a monoclonal antibody (MAb) against the reporter epitope. This approach led us to show that upon insertion after residues 153 and 374 of the mature LamB protein, the $\mathrm{C} 3$ epitope was expressed at the bacterial cell surface (8), indicating that these two regions of LamB face the outside of the cell as proposed by our folding model ( 9 , 10).

In this work, we used an improved procedure to identify eight new permissive sites. We provide data showing that the corresponding hybrid proteins are not strongly distorted with respect to wild-type LamB; thus, their study yields further information on the topology and organization of the LamB protein. We discuss the nature of permissive sites, the generalization of this approach to other proteins, and possible applications. 


\section{MATERIALS AND METHODS}

Strains, media, and chemicals. Strain pop6510 (thr leu tonB thi lacYl recA $\operatorname{dex}-5$ metA supE) was used as the recipient for all transformations; $d e x-5$ is a mutation in gene $\operatorname{lamB}$ that prevents adsorption of all known phages using the LamB protein as well as growth on dextrins (3). The parental plasmid pAC1 carrying the wild-type $\operatorname{lamB}$ gene, which was used for linker mutagenesis, has been described elsewhere (4). Since in all constructions the $\operatorname{lamB}$ modified genes were under ptac 12 promoter control, expression of the modified proteins was inducible by isopropyl- $\beta$ - $D$-thiogalactoside (IPTG). Basal expression of LamB from this plasmid corresponds approximately to 1,500 monomers per cell.

Phage $\lambda$ with the wild-type host range $(\lambda \mathrm{h}+)$ and its mutants with extended host range ( $\lambda \mathrm{h}$ and $\left.\lambda h^{*}\right)$ were described previously (6). $\lambda \mathrm{h}$ is a one-step mutant, while $\lambda \mathrm{hh}^{*}$ is a two-step mutant. Sensitivity to phages was determined either by cross-streaking or by determining the efficiency of plating by spot test on lawns of the different bacterial mutants, using $10^{-2}, 10^{-4}$, and $10^{-6}$ dilutions of each phage stock (4).

Media, chemicals, and growth conditions were as described previously (4). The 12-bp linker comprising the BamHI site (sequence 5'-CGCGGATCCGCG-3') was purchased from New England BioLabs. All other oligonucleotides were synthesized by Jean Igolen (Institut Pasteur) and purified on a $20 \%$ acrylamide-urea gel (8).

Two-step insertion of the $\mathrm{C3}$ epitope. (i) Linker insertion. Random linker mutagenesis in gene $\operatorname{lamB}$ was performed as described previously $(4,24)$. Briefly, plasmid pAC1 carrying the wild-type lamB gene was opened at random by treatment with DNase I, the ends were filled in by using the Klenow fragment of Escherichia coli DNA polymerase, the plasmid DNA was religated in the presence of an excess of unphosphorylated BamHI linker, and the DNA was transformed into the LamB-negative strain pop6510. Transformation of strain pop6510 was performed according to standard procedures (26), with selection for ampicillin resistance.

The transformants were then screened for sensitivity to phage $\lambda \mathrm{hh}^{*}$ by cross-streaking on complete liquid mediumampicillin plates. Of 550 transformants, 260 (approximately $50 \%$ ) were sensitive to $\lambda \mathrm{hh}^{*}$. Growth of $\lambda \mathrm{hh}^{*}$ is prevented only by mutations that affect drastically the LamB protein such as nonsense mutations or deletions (5). Consequently, most of the clones resistant to $\lambda \mathrm{hh}^{*}$ were expected to carry important modifications in the $\operatorname{lamB}$ gene and thus to have lost all functions. For this reason we retained essentially $\lambda \mathrm{hh}^{*}$-sensitive clones. These clones were further tested by restriction analysis. Double digestions of plasmid DNAs with BamHI and enzymes cutting only once in the plasmid, such as NcoI, StuI, and ClaI, analyzed by using $1.5 \%$ agarose gel, permitted us to localize the BamHI insertions. Over $80 \%$ of the transformant clones had inserted a BamHI linker. Twelve transformants (approximately 5\%) had inserted the BamHI linker within $\operatorname{lamB}$. Further studies revealed that nine of them were different.

Six $\lambda h^{*}$-resistant clones were also analyzed. They all corresponded to insertion of the Bam HI linker. Immunoblotting of total cellular extracts on nitrocellulose filters and detection with anti-LamB monomer serum showed that one of them expressed a LamB protein of the correct size. This clone, named JAV168, was able to grow on dextrins.

(ii) C3 epitope insertion. The double-stranded oligonucleotides corresponding to the three different reading frames of the $\mathrm{C} 3$ epitope, numbered phases 1,2 , and 3 (see below and

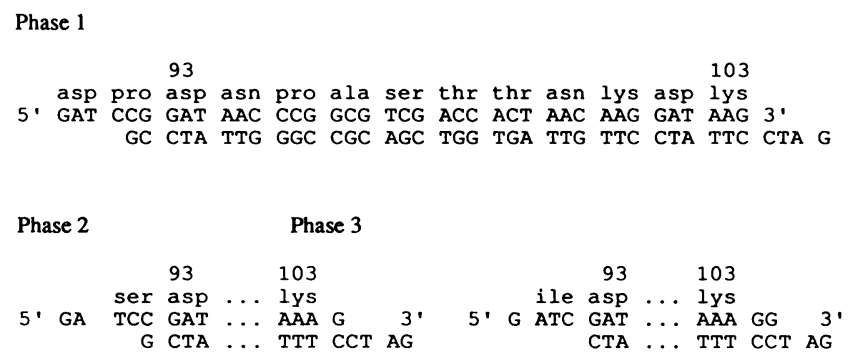

FIG. 1. Oligonucleotides encoding the $\mathrm{C} 3$ epitope from poliovirus. The three double-stranded oligonucleotides encode the $\mathrm{C} 3$ epitope in the three possible reading frames (phases 1,2 , and 3 ). The two first double-stranded oligonucleotides are flanked by BamHI sites. To obtain a short joint region, the proximal end of the phase 3 oligonucleotide is simply a BamHI cohesive end, while the distal end is a full BamHI site. The amino acid sequence of the 93-103 peptide carrying the C3 epitope from the VP1 protein of poliovirus type 1 is indicated above the sequence.

Fig. 1) were prepared by J. Igolen (Institut Pasteur, Paris) and purified on a $20 \%$ acrylamide-urea denaturing gel (8).

We knew from previous studies that an intact $\mathrm{COOH}$ terminal end was required for LamB activities (4). All of the BamHI inserts studied here conserved at least one of the activities of the protein, indicating that the reading frame was not shifted by the presence of the linker. Thus, three double-stranded oligonucleotides with an exact number of codons (13 in each case) were used.

Plasmid DNAs were linearized by digestion with restriction enzyme BamHI and purified on 5\% acrylamide gels (26). Since the oligonucleotides were unphosphorylated, each transformant obtained after subcloning of the C3 oligonucleotides corresponded either to the parental construction (no insertion) or to the insertion of a single double-stranded oligonucleotide. Statistically, if all of the transformants corresponded to the insertion of a double-stranded oligonucleotide, one of six clones should have inserted the correct phase of the C3 epitope in the correct orientation (correct frame, one in three; correct orientation, one in two). In all cases, we obtained between 30 and $70 \%$ of transformants with an insertion. Twenty clones from each transformation, tested by immunoblotting after heat denaturation with anti-C3 MAb (data not shown), were usually sufficient to select the good construction. In agreement with what was expected, in most cases approximately 10 to $20 \%$ of the clones assayed expressed the $\mathrm{C} 3$ epitope. This finding indicated that the subcloning procedure using a mixture of three phases of the oligonucleotides encoding the $\mathrm{C} 3$ epitope was efficient.

An equimolecular mixture of double-stranded oligonucleotides corresponding to the three different phases of the $\mathrm{C} 3$ sequence was used with all of the linker insertion mutants isolated except JAV183, for which only the oligonucleotide with phase 1 was used.

After transformation into strain pop6510, DNA restriction analysis and immunoblotting of total extracts with antiLamB monomer serum and anti-C3 MAb were performed in parallel on the clones generated. All of the LamB-C3 hybrid proteins constructed could be detected by both the antiLamB polyclonal serum and the anti-C3 MAb (Fig. 2).

DNA sequence determination. Oligonucleotides corresponding to nine segments of the $\operatorname{lamB}$ gene were used as primers for DNA sequence analysis. To allow convenient reading of the gels, these segments were separated by intervals of 150 bases. The first oligonucleotide started at the 
TABLE 1. BamHI linker and C3 epitope insertions

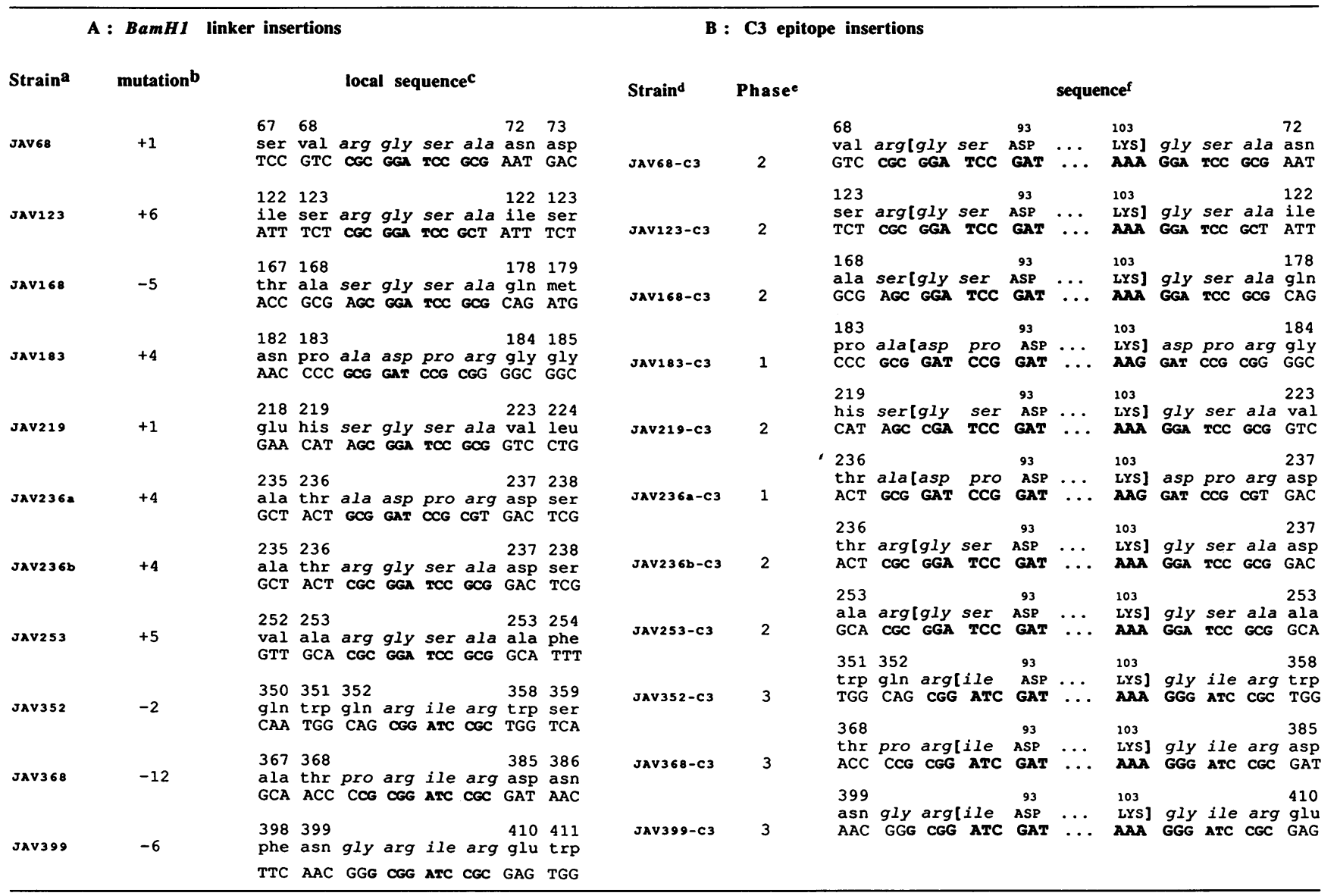

${ }^{a}$ All strains containing plasmids encoding modified LamB proteins are designated JAV, followed by the position of the last LamB residue before the mutation. ${ }^{b}$ Net number of residues added (+) or deleted $(-)$ by each mutation. All mutations except that of JAV352 include an insertion of four residues due to the BamHI linker. In the case of JAV352, only three residues were inserted.

c Numbers refer to residue positions in the mature LamB protein. In the protein sequence, residues due to the insertion of the BamHI linker are in italic letters. Only the coding strand of the DNA sequence is presented. Nucleotides from the linker are in bold characters; the cleavage site for Bam $\mathrm{HI}$ is between the two G's.

${ }^{d}$ Strains are designated JAV, followed by the position of the last residue before the mutation followed by C3.

e Defined by the oligonucleotide in the correct frame for expression of the C3 epitope, reflecting the position of the BamHI cleavage site with respect to the reading frame (see Fig. 1).

$f$ Residues from the LamB protein are indicated by roman letters, and their positions in LamB are shown by large numbers. Residues at the joint region are in italic letters. Only the first and last residues from the poliovirus 93-103 peptide are represented (capital letters). Nucleotides in large bold characters are from the $\mathrm{C} 3$ oligonucleotide; those in small bold characters are from the BamHI linker.

first base corresponding to the mature LamB protein. The sequences of the 9 primers (16-mers) were 5'-GTTGATTTC CACGGCT-3', 5'-AAGTGTGGAAAGAGGG-3', 5'-CTCCA CCATCTGGGCA-3', 5'-TCCTCTGAAGCTGGTG-3', 5'-G TCGTGCCAACTTGCG-3', 5'-GGGTAAAGGGCTGTCG-3', 5'-ATGTACCAGGATATCA-3', 5'-AGAACAATCAGTAC AA-3', AND 5'-CGCGAACTTCGGCAAA-3'.

Except for mutant JAV183, the sequence was determined on the construct with the $\mathrm{C} 3$ epitope insertion and the sequence of the linker insertion was deduced. For mutant JAV183, the sequences of both the linker and the C3 epitope insertions were deduced by knowing the sequence of $\operatorname{lamB}$ at the SmaI insertion site, the sequence of the 12-bp BamHI linker, and the sequence of the unique double-stranded $\mathrm{C} 3$ oligonucleotide used (phase 1).

The sequencing procedure was derived from the dideoxynucleotide method (2) by using rapid preparations of the plasmid DNA (26) from the different mutants as templates.
In each case, the approximate location of the insertion point was first determined by restriction enzyme analysis, and then the appropriate primer was chosen for elongation. Avian myeloblastosis virus reverse transcriptase (New England BioLabs) was used.

DNA sequencing revealed that three mutants were obtained twice. They were probably nonindependent clones arising from replication during transformation.

Sera. Three polyclonal anti-LamB sera were used. A serum raised in rabbits against the denatured LamB protein, which recognizes only the denatured LamB monomers, was used in Western immunoblotting experiments at a final dilution of $1 / 500$. It will be called anti-LamB monomer serum. The second was serum raised in mice against a synthetic peptide, corresponding to residues 69 to 83 of the mature LamB protein, chemically coupled to ovalbumin. This serum recognizes only the denatured LamB monomers (47) and was used in Western blotting experiments at a final 
dilution of $1 / 25,000$. It will be called anti-LamB peptide serum. The third was a serum raised in rabbits against the native LamB protein. This serum, which recognizes the denatured LamB monomers as well as trimeric and multimeric forms of LamB (8), was used in immunoprecipitation experiments at a final dilution of $1 / 50$. It will be called anti-LamB trimer serum.

A mouse MAb (called anti-C3 MAb), which recognizes specifically residues in the region from 93 to 103 of the VP1 protein of poliovirus type 1 , was used in Western blotting and immunoprecipitation experiments at final dilutions of $1 / 2,000$ and $1 / 50$, respectively. Anti-C $3 \mathrm{MAb}$ is a neutralizing antibody that reacts also with the 93-103 peptide (45).

The four anti-LamB MAbs used for enzyme-linked immunosorbent assay (ELISA) on intact bacteria were directed against cell surface-exposed determinants of LamB. Two of these antibodies (E177 and E302) had been shown to recognize determinants located within 70 residues of the $\mathrm{COOH}$ terminus of LamB (18). In addition, the sequence changes due to mutations yielding resistance to killing by complement in the presence of three of these antibodies (E302, E72, and E347) were located in loops around residues 333 and 390 (14).

Immunoblotting experiments. (i) Cellular extracts. Immunoblotting of heat-denatured cellular extracts of induced cultures was performed as described previously (4). Bacteria were grown at $37^{\circ} \mathrm{C}$ in liquid minimal medium supplemented with Casamino Acids (Difco Laboratories) and ampicillin and with glucose as a carbon source. At an optical density at $600 \mathrm{~nm}\left(\mathrm{OD}_{600}\right)$ of 0.5 , IPTG was added at a final concentration of $10^{-3} \mathrm{M}$. Depending on the mutation, three different situations occurred (Table 2): (i) when no inhibition of growth occurred, the culture was harvested at $\mathrm{OD}_{600}=1$; (ii) when the addition of IPTG led to a plateau, cells were harvested at this plateau; (iii) when addition of IPTG led to lysis of the culture, cells were harvested just at the onset of lysis. Cells were collected by centrifugation, resuspended, and concentrated 25 -fold into $\mathrm{H}_{2} \mathrm{O}$. Samples $(20 \mu \mathrm{l})$ of total cellular extracts were then collected, heat denaturated for 5 min at $100^{\circ} \mathrm{C}$ in loading buffer containing glycerol, sodium dodecyl sulfate (SDS), and $\beta$-mercaptoethanol, and run on $10 \%$ SDS-acrylamide gels.

After electrophoretic transfer to a nitrocellulose filter, the heat-denatured cellular extracts were analyzed with antiLamB monomer serum (Fig. 2A), anti-C3 MAb (Fig. 2B), and anti-LamB peptide serum (Fig. 2C). The antigen-antibody complexes were revealed by anti-immunoglobulin $\mathbf{G}$ (IgG) antibodies (anti-rabbit or anti-mouse) conjugated to horseradish peroxidase.

(ii) Purified LamB-C3 hybrid proteins. Purified LamB-C3 hybrid proteins were also tested by Western blot. They were prepared as described previously (19). Briefly, bacteria grown as described above were collected by centrifugation, resuspended in lysis buffer (2\% SDS, $10 \%$ glycerol, $2 \mathrm{mM}$ $\mathrm{MgCl}_{2}, 10 \mathrm{mM}$ Tris hydrochloride, $\mathrm{pH} 7.4$ ), and incubated 30 min at $60^{\circ} \mathrm{C}$. The membrane fraction containing the peptidoglycan was pelleted by ultracentrifugation at $100,000 \times g$ for $1 \mathrm{~h}$. The LamB-C3 hybrid proteins were then solubilized from the pellet by incubation overnight at $4^{\circ} \mathrm{C}$ in extraction buffer (2\% Triton X-100, $10 \mathrm{mM}$ Tris hydrochloride, $\mathrm{pH} 7.4$ ). After centrifugation at $100,000 \times g$ for $1 \mathrm{~h}$, the LamB-C3 hybrid proteins were recovered in the supernatant and concentrated (in 1-ml final volume from $50 \mathrm{ml}$ of culture). Extracts $(10 \mu \mathrm{l})$ were then heat denatured for $5 \mathrm{~min}$ at $100^{\circ} \mathrm{C}$ in loading buffer and run on $10 \%$ SDS-acrylamide gels as described above.
Immunoprecipitation under nondenaturing conditions. Immunoprecipitations were performed as described previously (8), with some modifications, using either the anti-LamB trimer serum or anti-C3 MAbs. Cells were grown at $37^{\circ} \mathrm{C}$ in liquid minimal medium supplemented with leucine, threonine, methionine, and ampicillin and with glucose as a carbon source. At $\mathrm{OD}_{600}=0.6$, cells were induced for 10 min with IPTG and then labeled with $\left[{ }^{35}\right.$ S $]$ methionine for 40 min. Bacteria were harvested by centrifugation and washed, and the pellet was resuspended in $50 \mathrm{mM}$ glucose- $10 \mathrm{mM}$ EDTA-25 mM Tris (pH 8.0)-4 mg of lysozyme per ml. After $5 \mathrm{~min}$ at room temperature, spheroplasts were lysed by addition of $2 \%$ SDS-5 mM EDTA (final concentration), followed by $10 \mathrm{~min}$ of incubation at $37^{\circ} \mathrm{C}$. These extracts were then diluted 10 -fold to lower the SDS concentration in $0.9 \%$ Triton $X-100-5 \mathrm{mM}$ EDTA-50 mM Tris ( $\mathrm{pH} 8.0)-0.1 \%$ ovalbumin, mixed with antiserum, and incubated at room temperature for $30 \mathrm{~min}$. After addition of protein A-Sepharose gel $(10 \%)$, incubation was continued for $15 \mathrm{~min}$ and the purified mutant LamB proteins were recovered in the centrifugation pellet. The pellet was resuspended in $30 \mu \mathrm{l}$ of loading buffer (60 mM Tris [pH 6.8], 10\% glycerol, $2 \%$ SDS, $0.05 \%$ bromophenol blue) and incubated at $37^{\circ} \mathrm{C}$ for $5 \mathrm{~min}$ before SDS-polyacrylamide gel electrophoresis (PAGE). The LamB protein and its derivatives were detected by autoradiography.

RIA. Radioimmunoassays (RIAs) were performed in 1.5-ml Eppendorf tubes on induced liquid cultures prepared as described above. A 50- $\mu$ l sample of each culture at $\mathrm{OD}_{600}$ $=1$ was mixed with $50 \mu$ l of phosphate-buffered saline (PBS) with $0.5 \%$ bovine serum albumin (BSA) (PBS-BSA), washed by centrifugation, and resuspended in $100 \mu$ l of PBS-BSA so that the final $\mathrm{OD}_{600}$ per assay was 0.5 . Then $10 \mu$ l of a $1 / 100$ dilution of $\mathrm{C} 3 \mathrm{MAb}$ in PBS-BSA was added, and the mixture was incubated for $1 \mathrm{~h}$ at $37^{\circ} \mathrm{C}$ under agitation. After two washes with $250 \mu$ l of PBS-BSA, the pellets were resuspended in $250 \mu$ l of a dilution of ${ }^{125} \mathrm{I}$-protein A (Amersham) in the same buffer, containing approximately $100,000 \mathrm{cpm}$. The resuspended pellets were incubated for $1 \mathrm{~h}$ at room temperature, washed twice in PBS-BSA, and counted in a gamma counter. The Fc fragment of the subclass of mouse anti-C3-IgG in the ascitic fluid was well recognized by protein $\mathrm{A}$. We showed previously that it corresponds to the IgG2A subclass (25).

ELISA with anti-LamB MAbs. ELISA was performed on intact cells in microtitration plates (30). Strains were grown in liquid minimal medium with glucose as a carbon source and Casamino Acids. Hybrid protein expression was induced by addition of IPTG $\left(10^{-3} \mathrm{M}\right.$, final concentration) in early $\log$ phase $\left(\mathrm{OD}_{600}=0.4\right)$, and growth was pursued up to $\mathrm{OD}_{600}=1$. Cells were then washed and resuspended in PBS. Plates were coated with $5 \times 10^{6}$ bacteria $(100 \mu l$ per well of a bacterial dilution at $\mathrm{OD}_{600}=0.1$ in PBS). After overnight incubation at $37^{\circ} \mathrm{C}$, the excess of antigen was discarded and wells were saturated with $250 \mu$ l of PBS containing $0.5 \%$ gelatin for $1 \mathrm{~h}$ at $37^{\circ} \mathrm{C}$. Then $100 \mu$ l of dilutions of MAbs E-302, E-72, E-177, and E-347 was added at a final dilution of $1 / 5,000$. After extensive washes, antigen-antibody complexes were developed by peroxidase-labeled anti-mouse antibodies $\left(1 \mathrm{~h}\right.$ at $\left.37^{\circ} \mathrm{C}\right)$ and $2-2^{\prime}$-azino-di-(3-ethylbenzthiazoline sulfonic acid) for $20 \mathrm{~min}$ at room temperature. Values were recorded at $420 \mathrm{~nm}$. Assays were performed simultaneously on LamB-positive (strain AC1) and -negative (pop6510) controls. Three determinations were done for each assay.

Protease sensitivity assays. The assays were conducted in 
three steps on bacterial lysates. First, induced hybrid proteins were labeled with $\left.{ }^{35} \mathrm{~S}\right] \mathrm{methionine}$ and the cells were lysed. Second, the lysates were incubated in the presence of trypsin. Third, the digestion products were immunoprecipitated, after denaturation, with anti-LamB trimer serum.

(i) Preparation of bacterial samples for trypsin treatment. Cells were grown at $37^{\circ} \mathrm{C}$ in liquid minimal medium 63B1 with $0.2 \%$ glucose as a carbon source, supplemented with ampicillin $(100 \mu \mathrm{g} / \mathrm{ml})$, threonine and leucine $(0.01 \%)$, and methionine $(0.001 \%)$. IPTG was added $\left(10^{-3} \mathrm{M}\right.$, final concentration) to exponential-phase cultures at $\mathrm{OD}_{600}=0.5$, and growth was continued. At $10 \mathrm{~min}$ after induction with IPTG, cells were labeled with $\left[{ }^{35} \mathrm{~S}\right]$ methionine $(10 \mu \mathrm{Ci} / \mathrm{ml}$ of cell culture) for $\mathbf{4 0} \mathrm{min}$. Bacteria were harvested by centrifugation and resuspended in lysis buffer $(50 \mu \mathrm{l} / \mathrm{ml}$ of culture; $30 \mathrm{mM}$ Tris [pH 8], 20\% sucrose, $2.5 \mathrm{mM}$ EDTA, $2 \mathrm{mg}$ of lyzozyme per $\mathrm{ml}$ ). Suspensions were then incubated at room temperature for $15 \mathrm{~min}$; $950 \mu \mathrm{l}$ of $30 \mathrm{mM}$ Tris (pH 8)-2.5 mM EDTA was added to each preparation, which was then cooled at $4^{\circ} \mathrm{C}$.

(ii) Trypsin treatment. Bacterial lysates were incubated for $1 \mathrm{~h}$ at $37^{\circ} \mathrm{C}$. A final trypsin concentration of $100 \mu \mathrm{g} / \mathrm{ml}$ was used. Control samples (without enzyme) were incubated in the same conditions. Reactions were stopped by addition of trichloroacetic acid (5\%, final concentration) and stored at $4^{\circ} \mathrm{C}$ for $15 \mathrm{~min}$.

(iii) Immunoprecipitation. After treatment, the trichloroacetic acid precipitates were washed once with acetone and dried. The pellets were dissolved in lysis buffer $(25 \mathrm{mM}$ Tris [pH 8], $10 \mathrm{mM}$ EDTA, $50 \mathrm{mM}$ glucose, $4 \mathrm{mg}$ of lysosyme per $\mathrm{ml}, 2 \% \mathrm{SDS})$, followed by $10 \mathrm{~min}$ of incubation at $100^{\circ} \mathrm{C}$. The samples were then diluted 10 -fold in $50 \mathrm{mM}$ Tris (pH 8)-0.9\% Triton X-100-5 mM EDTA-0.1\% ovalbumin. Incubations with anti-LamB trimer serum were done as described previously (8).

\section{RESULTS}

Our aim was to insert the $\mathrm{C} 3$ epitope at different sites in LamB and then to use the anti-C3 MAb to probe the location of the $\mathrm{C} 3$ epitope with respect to the outer membrane and to the LamB protein itself. In the absence of structural data, to ensure that the topological conclusions drawn for the LamB-C3 hybrid proteins were valid for the wild-type LamB protein, we used a number of tests to evaluate the degree of deformation of the hybrid proteins. These tests included LamB activities, recognition by various anti-LamB sera, and cellular toxicity of the hybrids. Each of these tests provided only partial information on folding and location, but their combination generally led to convergent arguments and therefore stronger conclusions.

Insertion of a BamHI linker. The first step in the improved procedure to detect permissive sites consisted in the random insertion of a BamHI linker encoding four amino acid residues into the $\operatorname{lam} B$ gene and screening for mutant clones still presenting at least one of the in vivo biological activities of the LamB protein: phage adsorption and maltodextrin utilization. The corresponding mutations indicated segments able to accommodate limited genetic changes without major alterations of the protein location and structure, i.e., potential permissive sites.

Gene lamB was carried on plasmid $\mathrm{pAC} 1$ and thus inducible by IPTG (4). In the absence of an inducer, the basal expression of gene $\operatorname{lamB}$ is sufficient to promote sensitivity to phage $\lambda$ and growth on maltodextrins (see Materials and Methods).
After random insertion of the BamHI linker, selection was performed for ampicillin-resistant transformants in a strain devoid of an active $\operatorname{lamB}$ gene (pop6510), followed by screening for sensitivity to a mutant of phage $\lambda$ with the most extended host range (the two-step mutant $\lambda h^{*}$ ). Such a screening procedure eliminated mutants with drastic alterations in LamB (5). From $260 \lambda \mathrm{hh}^{*}$-sensitive clones, we found and kept for further studies 9 clones having a $\mathrm{BamHI}$ linker inserted within gene $\operatorname{lamB}$. We also selected for further studies a $\lambda h^{*}$-resistant clone that was able to grow on maltodextrins as a carbon source and expressed a normalsized LamB protein. This clone was named JAV168. A supplementary mutant was constructed by inserting directly the BamHI linker into the natural SmaI restriction site of gene lamB located after amino acid 183 of the mature protein in a region proposed to face the periplasm. The corresponding clone was sensitive to phage $\lambda$ and proficient for growth on maltodextrins. It was named JAV183.

In summary, we isolated 11 clones expressing a LamB protein modified by the insertion of a BamHI linker and presenting at least one of the activities of this protein. These clones were named JAV, followed by a number representing the position of the last $\mathrm{LamB}$ residue preceding the insert (see below). The corresponding genes and proteins were named lamBJAV and LamBJAV, followed by the same number.

The 11 mutant proteins were examined by immunoblotting of heat-denatured bacterial extracts with anti-LamB monomer serum. The mutants all yielded a single band corresponding to the monomeric form of LamB (Fig. 2A). Three mutants (JAV352, JAV368, and JAV399) presented fainter bands. A simple and most likely reason for this finding is that all three occurred in the $\mathrm{COOH}$-terminal region, which contains major antigenic determinants of $\operatorname{LamB}(14,18$; Table 2).

All of these data are compatible with the idea that the linker insertion mutant proteins are essentially stable in vivo. This view is further supported by results for the LamB-C3 hybrid proteins (see below).

Insertion of the $\mathrm{C3}$ epitope. The second step consisted in inserting an oligonucleotide encoding the reporter epitope into the new BamHI sites created in each of these clones. We used the well-defined C3 neutralization epitope from poliovirus. This continuous epitope is included within an 11-residue peptide (23). Except for JAV183, the position of the cleavage site for $B a m H I$ with respect to the reading frame in $\operatorname{lamB}$ was not known. Therefore, cloning in all other cases was performed with a mixture of three doublestranded oligonucleotides encoding the C3 epitope from poliovirus in the three different possible reading frames (named phases 1, 2, and 3; Fig. 1), followed by immunoscreening of the clones expressing the foreign epitope. For JAV183, only the oligonucleotide with phase 1 was used.

As expected, approximately one insertion event out of six led to a protein that was recognized by the anti-C3 MAb by immunoblotting of heat-denatured bacterial extracts (Fig. 2B). For each hybrid, a single band corresponding to the monomeric form was detected. Because there was some variation in the band intensities, we performed the same experiment with a serum directed against the 69-83 peptide of LamB (see Materials and Methods) with all except two LamB-C3 hybrids (insertions at sites 168 and 368, which proved not permissive; see below). The bands corresponding to the LamB-C3 hybrid proteins had roughly comparable intensities (within a factor 5) (Fig. 2C). Since the variations were generally not correlated with those observed with the 

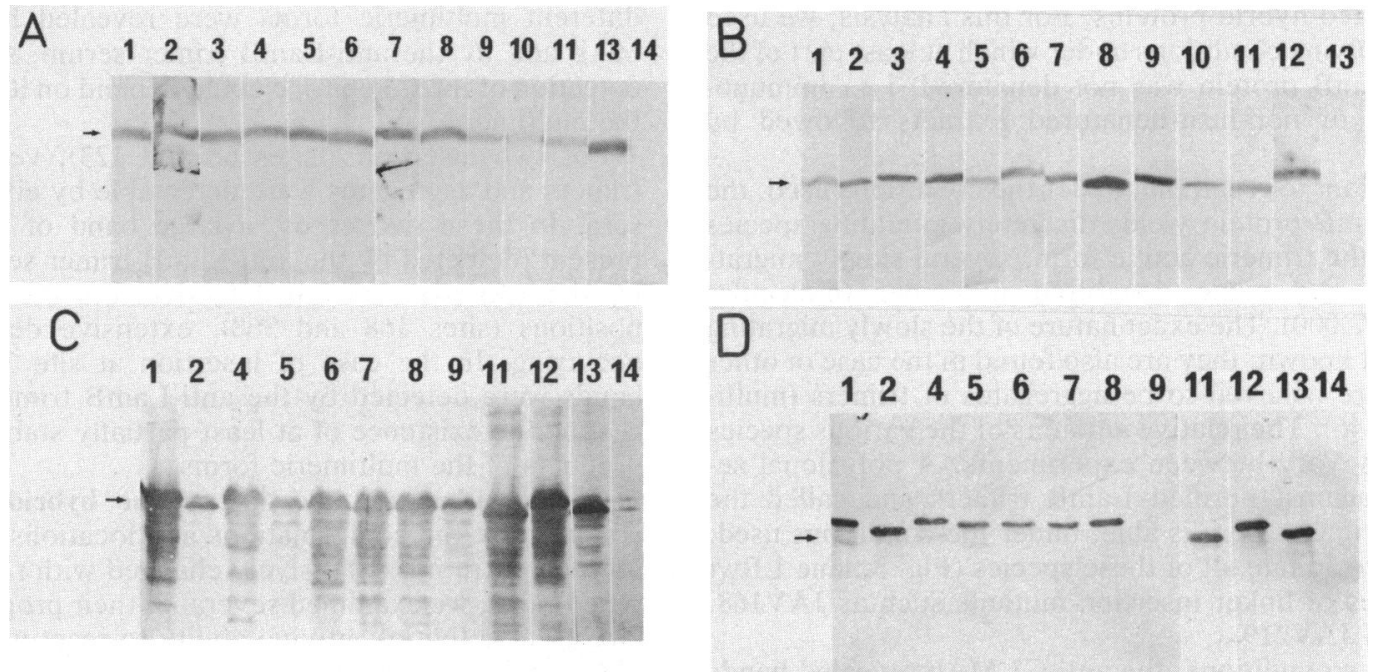

FIG. 2. Immunoblotting under denaturing conditions. Heat-denatured bacterial extracts of various mutant strains (A to C) and heat-denatured purified hybrid proteins (D) were loaded onto $10 \%$ SDS-acrylamide slab gels. Lanes: 1, JAV68-C3; 2, JAV123-C3; 3, JAV168-C3; 4, JAV183-C3; 5, JAV219-C3; 6, JAV236a-C3; 7, JAV236b-C3; 8, JAV253-C3; 9, JAV352-C3; 10, JAV368-C3; 11, JAV399-C3; 12, AJC264-VP1; 13, AC1; 14, pop6510. In panel A, lanes 1 to 11 correspond to the linker insertion mutants; in panels $B$ to $D$, they correspond to the LamB-C3 hybrids. (A) Extracts of linker insertion mutants; detection with anti-LamB monomer serum. (B) Extracts of LamB-C3 mutants; detection with anti-C3 serum. (C) Extracts of LamB-C3 mutants; detection with anti-LamB peptide serum. (D) Purified LamB-C3 protein; detection with anti-LamB peptide serum. In panels $A, C$, and $D$, the positive control was strain AC1 expressing the wild-type LamB protein (lane 13), and the negative control was the LamB-negative strain pop6510 (lane 14). In panel B, the positive control was strain AJC264-VP1 expressing a LamB-C3 hybrid protein previously described (8) (lane 12), and the negative control was strain AC1 expressing the wild-type LamB protein (lane 13).

anti-C3 MAb, we concluded that there were no large variations in amount (and therefore stability) of the hybrid proteins. In agreement with this interpretation, purification of the LamB-C3 hybrid proteins, followed by immunoblotting with the anti-LamB peptide serum, also revealed bands with comparable intensities (within a factor 5) (Fig. 2D). The only exception was mutant JAV352-C3, for which no band was detected. Our interpretation is that the purification procedure (based on peptidoglycan extraction; see Materials and Methods) is not valid for this mutant protein, which is probably altered in its interaction with the peptidoglycan.

The nomenclature was deduced from that of the linker insertions by adding C3. For example, JAV183, a clone with a linker insertion, yielded JAV183-C3, a clone expressing the hybrid protein LamBJAV183-C3.

The DNA sequence of the hybrid genes was determined at the site of the insert by extension of a primer with the dideoxy sequencing method. The 11 linker mutations were distinct, although 2 of them corresponded to an insertion at the same site in LamB, after residue 236 (Table 1A). These two mutations could be distinguished because the reading frame of the linker was different.

Five mutants, JAV123, JAV183, JAV236a, JAV236b, and JAV253, were due to insertions without concomitant deletions in the adjacent LamB sequence. In two of them, JAV123 and JAV253, the insertions were even accompanied by a short duplication of two and one amino acid of LamB, respectively, at the insertion site. For the six other mutants, JAV68, JAV168, JAV219, JAV352, JAV368, and JAV399, deletions of 3 to 16 residues occurred in the LamB sequence at the insertion site. Secondary mutations due to linker insertion are frequent (see, for example references 4 and 15).

Exposure of $\mathbf{C 3}$ at the bacterial surface. We first examined whether the $\mathrm{C} 3$ epitope was exposed on the bacterial surface and for this purpose developed an RIA. Briefly, appropriate concentrations of bacteria and $\mathrm{C} 3 \mathrm{MAb}$ were incubated together. Binding of the antibody to the cells was revealed by using ${ }^{125} \mathrm{I}$-protein $\mathrm{A}$. After incubation with protein $\mathrm{A}$, cells were collected by centrifugation; the counts recorded for the bacterial pellets reflected the amount of ${ }^{125}$ I-protein A bound to the complexes formed by the LamB-C3 hybrid and C3 MAb on bacterial cells. As positive controls we used the two strains already known to express the C3 epitope at their surface (strain AJC264-VP, with C3 at site 153 in LamB; strain AJC178-VP, with $C 3$ at site 374 ) (8). The signal obtained with these strains was over 100 times that obtained with a wild-type LamB strain (Table 2).

With the new constructions, only the $\mathrm{C} 3$ insertion at site 253 yielded a positive signal. This signal was comparable to that found at site 374. All other $\mathrm{C} 3$ insertions gave a signal/background ratio of less than 2.4 , which we consider not significant (Table 2). These results were confirmed by using an ELISA in which intact bacteria were coated on microtiter plates (30). In agreement with the results of the RIA, the only case in which a positive signal was recorded with the new constructions was the C3 insertion at site 253 (data not shown).

This analysis showed that the $\mathrm{C} 3$ epitope inserted at site 253 is exposed at the cell surface. In the other cases, the absence of detection at the cell surface could correspond to one of two situations: either the $\mathrm{C} 3$ epitope is detectable on the isolated hybrid protein but unaccessible from the cell surface or the $\mathrm{C} 3$ epitope is undetectable on the isolated hybrid protein (constrained conformation or not located on the surface of the hybrid protein).

Exposure of $\mathrm{C} 3$ on the hybrid proteins. To distinguish between these two possibilities, we examined whether the $\mathrm{C} 3$ epitope could be detected by the $\mathrm{C} 3 \mathrm{MAb}$ at the surface 
of the extracted hybrid proteins. For this analysis, we used an assay involving conditions under which at least part of the wild-type LamB protein was not denatured, i.e., immunoprecipitation of non-heat-denatured extracts followed by SDS-PAGE.

It is important to recall that under the conditions used, the wild-type LamB protein yields discretely migrating species that include the trimeric active form, several slowly migrating species, and some denatured monomer (molecular weight of $\sim 47,000$ ). The exact nature of the slowly migrating species is not known: they are also found in the case of other porins and are believed to be aggregates of trimers (multimers) $(8,41,46)$. The relative amounts of the various species detected may vary between experiments. A polyclonal serum raised against purified LamB trimers and called the anti-LamB trimer serum is able, under the conditions used, to immunoprecipitate all of these species (Fig. 3, lane LBwt and first lanes of linker insertion mutants such as JAV168, JAV183, and JAV219).

Under these conditions, the anti-C3 MAb revealed bands migrating as trimers (and/or aggregates of trimers) in the case of hybrid proteins corresponding to insertions at five positions: sites $183,219,236,253$, and 352 . We concluded that at these positions, the $\mathrm{C} 3$ epitope was exposed at the surface of the native LamB hybrid protein in a conformation in which it reacted with the anti-C3 MAb. Interestingly, the two hybrid proteins corresponding to insertion of the $\mathrm{C} 3$ epitope at site 236 were not identically detected by the anti-C3 MAb: while trimeric and monomeric forms of hybrid Lam BJAV236a-C3 were clearly detected, there was no or very little detection of hybrid LamBJAV236b-C3. This result agrees with the idea that the flanking sequences may play a critical role in the antigenicity of the C3 epitope (44).

At site 253, the epitope was detected in vitro as well as on the cell surface. This result was expected if the conformations of the hybrid protein are similar in vitro and in vivo. Assuming that this condition was valid for the other hybrid proteins, we further concluded that at the four other sites the C3 epitope was not accessible to the antibody at the cell surface. This was predicted by our model for sites 183 and 352, which face the periplasm (Fig. 1). The cases of sites 219 and 236 are more complex and will be further examined in Discussion.

Trimeric forms of the hybrid proteins corresponding to the five remaining sites $(68,123,168,368$, and 399$)$ were not or very poorly detected with the $\mathrm{C} 3 \mathrm{MAb}$, possibly because trimeric forms were present but the $\mathrm{C} 3$ epitope was not detected (it was buried within the hybrid protein or was exposed but constrained) or because the trimeric form was lacking in these experimental conditions (perhaps as a result of degradation or poor association between subunits).

In vitro detection of trimers. To discriminate between these alternatives, we used the anti-LamB trimer serum and examined by the same technique the LamB-C3 hybrid proteins.

For three positions (sites 219, 236, and 253) trimers, multimers, or both were revealed by both the $\mathrm{C} 3 \mathrm{MAb}$ and the anti-LamB trimer polyclonal antibody, showing that not only the $\mathrm{C} 3$ epitope but also the major epitopes recognized by the anti-LamB trimer serum were exposed and detected on the corresponding trimeric hybrid proteins. For one position (site 399) trimers were seen, but only with the anti-LamB trimer serum; this finding indicated that trimers were present but that the $\mathrm{C} 3$ epitope was not detected by the MAb because of incorrect exposure or conformation (see Discussion). Interestingly, for another position (site 183), different multimeric forms were revealed by the anti-C3 $\mathrm{MAb}$ and by the anti-LamB trimer serum, suggesting that detection of the $\mathrm{C} 3$ epitope could depend on its exact state in the multimers.

For two insertions (sites 68 and 123), very little or no trimers and aggregates were detectable by either of the two sera. In these two cases, a large band of monomer was present (detected by the anti-LamB trimer serum), suggesting that trimerization was defective. For the two remaining positions (sites 168 and 368 ), extensive degradation was occurring. In the case of insertion at site 368 , numerous bands were detected by the anti-LamB trimer serum, suggesting the existence of at least partially stable degradation products of the multimeric forms.

Conformation and location of the hybrid proteins. To confirm that the conformations and locations of the mutant proteins were not extensively changed with respect to wildtype LamB, we examined several of their properties: in vivo biological activities, in vivo ability to react with anti-LamB $\mathrm{MAb}$, in vitro sensitivity to trypsin, and toxic effects of overproduction.

(i) In vivo biological activities. With regard to biological activities, two of the $\mathrm{C} 3$ insertion mutations, at sites 183 and 219, were silent: the corresponding strains were sensitive to phage $\lambda \mathrm{h}+$ (and consequently to both of its extended-hostrange mutants) and able to ferment maltodextrins. Seven other C3 insertions affected at least partially one of the two functions but did not abolish both of them; they were specific mutations. All seven preserved at least some activity toward phage $\lambda$ (or host range mutants); in four cases, at sites $236 \mathrm{a}$, 236b, 253, and 399, maltodextrin fermentation was not affected, while in three other cases, at sites 68,123 , and 352 , growth on maltodextrins was affected to different extents. The last two insertions, at sites 168 and 368, abolished both functions.

In summary, insertion of $\mathrm{C} 3$ preserved at least partially both activities at six sites and at least one of the activities at two sites ( 68 and 123 ). Thus, 8 of the 10 potential permissive sites retained after the first screening step because they preserved at least one of the activities of LamB proved permissive for insertion of C3. This result shows that our screening based on linker insertion is an efficient way to detect permissive sites.

(ii) In vivo detection with anti-LamB MAb. Four MAbs recognize conformational determinants of the cell surfaceexposed regions of $\mathrm{LamB}$ located after residue $330(14,18)$. They could therefore be used to examine changes in the conformation or the exposure of these determinants.

Intact bacteria expressing the LamB linker insertion mutants and the LamB-C3 hybrid proteins were tested in an ELISA with these four MAbs (Table 2). The signals to all four MAbs were essentially abolished only for the two hybrid proteins corresponding to the nonpermissive sites (168 and 368). At the other (permissive) sites, insertion of the C 3 epitope essentially conserved the ELISA signal (sites 68 , 183,236 , and 253), suggesting that no or little change had occurred in the COOH-terminal part of the protein (after residue 330 ), or maintained a clear positive signal for at least one of the MAbs (sites 123, 219, 352, and 399), excluding the existence of major changes in conformation or location.

We thus observed a correlation between the loss of activities in the LamB-C3 hybrid proteins and the loss of reactivity toward the MAbs (Table 2). All of the results confirmed that insertion of the $\mathrm{C} 3$ epitope at the eight permissive sites produced no or only limited distortions in regions distant from the insert on the linear sequence. The 


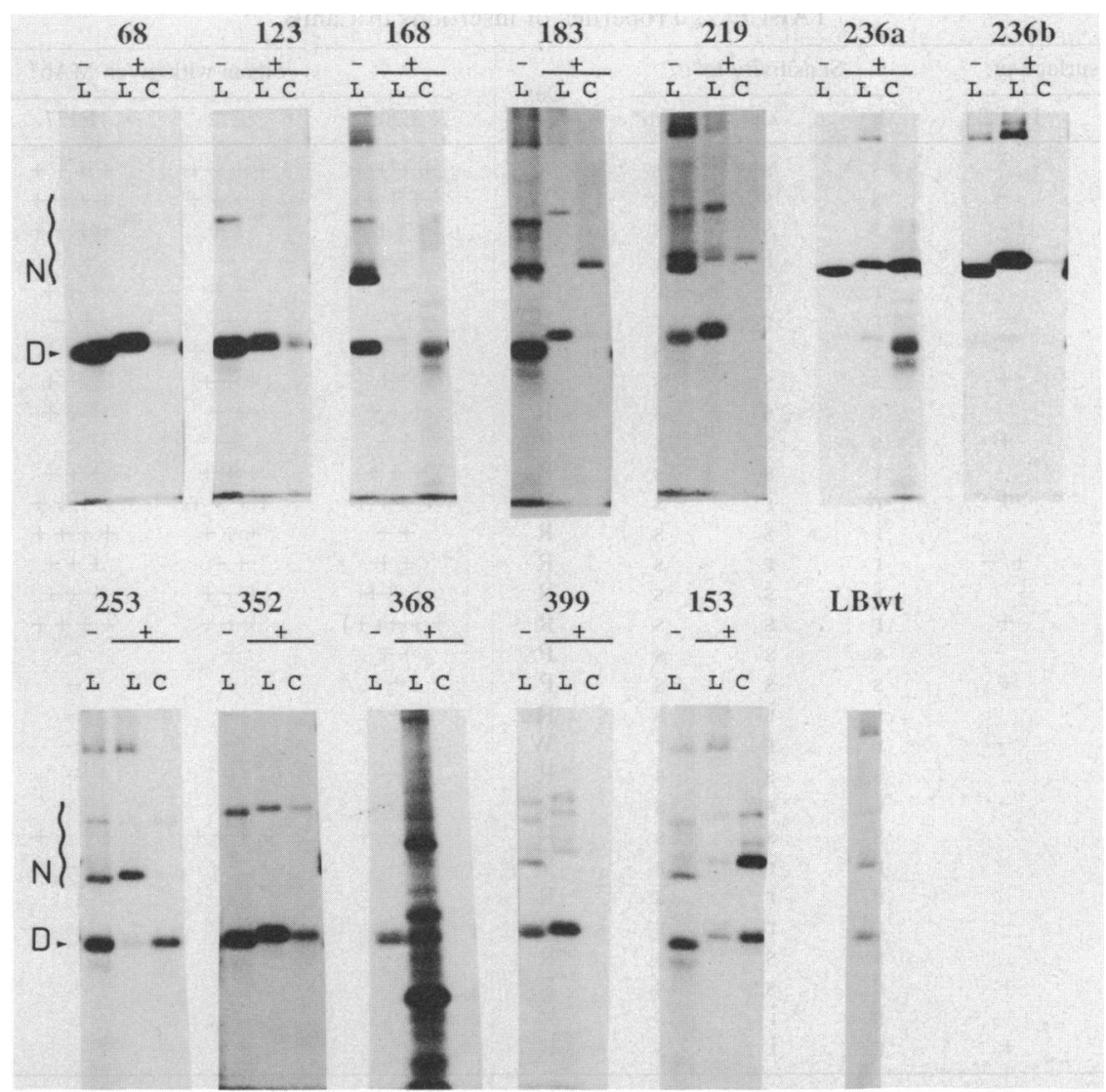

FIG. 3. Immunoprecipitation of non-heat-denatured extracts, using either anti-LamB trimer or anti-C3 MAb. The amino acid position of the insert is indicated above each set of lanes. At each site, the results with the $C 3$ insert $(+)$ and with the linker alone $(-)$ are shown. Lanes $\mathrm{L}$ and $\mathrm{C}$ correspond to anti-LamB and anti-C3 sera, respectively. D (denatured) indicates the migration of the monomeric form of the hybrid; $\mathrm{N}$ (native) indicates the trimeric or multimeric forms of the hybrids. Insertion of the $\mathrm{C} 3$ epitope at site 153 (previously described [8]) is also shown. Lane LBwt represents detection of the wild-type LamB protein with anti-LamB serum.

existence of some limited deformations in several cases could be due to long-distance effects along the polypeptidic chain but also possibly to proximity on the three-dimensional structure.

(iii) In vitro sensitivity to trypsin. The LamB protein is naturally very resistant to trypsin (40). We have shown that insertion of the $\mathrm{C} 3$ epitope can lead to trypsin sensitivity and that cleavage sites usually occur within or near the insert (39).

When the LamB-C3 hybrid proteins constructed in this study were treated with trypsin in cellular extracts, they could be divided into two classes (data not shown). Class I displayed one major band corresponding to a cleavage site at or near the insert. It included all of the hybrid proteins that were detected with all four MAbs (C3 inserted at sites 68, $183,236 \mathrm{a}, 236 \mathrm{~b}$, and 253) as well as site 399 , for which the C3 insertion occurred at or near the MAb sites. This finding is in agreement with the idea that in these cases deformation due to $\mathrm{C} 3$ insertion was restricted to the region of the insert. Class II was extensively degraded. It included only proteins that were not detected by at least one of the MAbs (insertion at sites $123,168,219,352$, and 368 ), in agreement with the hypothesis that deformations in these proteins were more severe and had unmasked other protease-sensitive sites.

The only exception was LamBJAV368-C3. This hybrid protein was trypsin resistant despite the fact that by all criteria it was one of the most distorted of the hybrid proteins. The reasons for this are not known.

(iv) Toxicity upon overproduction. When expressed at the basal level, none of the mutated proteins isolated prevented cell growth. Upon full induction, the amount of LamB protein synthesized from the plasmid used (pAC1) was increased about 30 -fold. It was already known that induction at this level of a number of mutant LamB proteins was toxic to the cell (4). Toxicity reflects various abnormalities in the level of expression, export, folding, maturation, or membrane insertion of the LamB derivatives (see Discussion).

Induction affected cell growth for all linker insertion mutants except one (Table 2). Since a number of the genetic modifications yielding toxicity were otherwise silent (for example, at sites 183 and 219 ), this finding confirmed that toxicity is a sensitive criterion for detection of abnormalities in the mutant proteins. Interestingly, the only nontoxic linker insertion mutant corresponded to site 253 , which leads to cell surface exposure of the $\mathrm{C} 3$ epitope; the related LamB-C3 hybrid was also nontoxic, showing that genetic modifications are indeed well tolerated at this site.

Surprisingly, three LamB-C3 hybrid proteins (sites 123, 168 , and 368) were less toxic than the corresponding linker insertion mutants. A possible interpretation is given in Discussion. 
TABLE 2. Properties of insertions in LamB

\begin{tabular}{|c|c|c|c|c|c|c|c|c|c|c|c|}
\hline \multirow{2}{*}{ Strain $^{a}$} & \multicolumn{2}{|c|}{ C3 at surface of: } & \multicolumn{3}{|c|}{ Sensitivity to ${ }^{b}:$} & \multirow{2}{*}{$\operatorname{Dex}^{c}$} & \multicolumn{4}{|c|}{ Signal with given $\mathrm{MAb}^{d}$} & \multirow{2}{*}{ Growthe } \\
\hline & Celf & $\operatorname{LamB}^{8}$ & $\lambda \mathrm{h}+$ & $\lambda \mathbf{h}$ & $\lambda \mathrm{hh}^{*}$ & & E302 & E72 & E177 & E347 & \\
\hline JAV68 & & & $\mathbf{s}$ & $\mathbf{s}$ & $\mathbf{s}$ & $\mathbf{R}$ & ++++ & ++++ & ++++ & ++++ & $\mathbf{P}$ \\
\hline JAV68-C3 & 164 & - & $\mathbf{s}$ & $\mathbf{s}$ & $\mathbf{s}$ & W & +++ & ++++ & ++++ & ++++ & $\mathbf{P}$ \\
\hline JAV123 & & & $\mathbf{s}$ & $\mathbf{s}$ & $\mathbf{s}$ & $\mathbf{R}$ & ++++ & ++ & ++++ & +++ & L \\
\hline JAV123-C3 & 210 & - & $\mathbf{r}$ & $\mathrm{i}$ & $\mathrm{i}$ & $\mathbf{W}$ & ++ & - & $+1-$ & - & $\mathbf{N}$ \\
\hline JAV168 & & & $\mathbf{r}$ & $r$ & $r$ & $\mathbf{R}$ & ++ & ++ & +++ & +++ & L \\
\hline JAV168-C3 & 90 & - & $\mathbf{r}$ & $\mathbf{r}$ & $\mathbf{r}$ & W & $+1-$ & - & $+1-$ & - & $\mathbf{N}$ \\
\hline JAV183 & & & $\mathbf{s}$ & $\mathbf{s}$ & $\mathbf{s}$ & $\mathbf{R}$ & ++++ & ++++ & +++ & +++ & $\mathbf{L}$ \\
\hline JAV183-C3 & 190 & + & $\mathbf{s}$ & $\mathbf{s}$ & $\mathbf{s}$ & $\mathbf{R}$ & ++++ & +++ & +++ & +++ & $\mathbf{P}$ \\
\hline JAV219 & & & $\mathbf{s}$ & $\mathbf{s}$ & $\mathbf{s}$ & $\mathbf{R}$ & +++ & ++ & +++ & ++ & L \\
\hline JAV219-C3 & 228 & + & s & s & s & $\mathbf{R}$ & ++ & - & + & - & $\mathbf{P}^{*}$ \\
\hline JAV236a & & & $\mathbf{r}$ & $\mathbf{s}$ & $\mathbf{s}$ & $\mathbf{R}$ & +++ & +++ & +++ & +++ & $\mathbf{P}$ \\
\hline JAV236a-C3 & 172 & + & $\mathbf{r}$ & i & $\mathbf{s}$ & $\mathbf{R}$ & ++++ & ++++ & ++++ & ++++ & $\mathbf{P}^{*}$ \\
\hline JAV236b & & & i & $\mathbf{s}$ & s & $\mathbf{R}$ & ++ & +++ & ++++ & +++ & $\mathrm{P}^{*}$ \\
\hline JAV236b-C3 & 324 & $+1-$ & $\mathbf{r}$ & $\mathbf{r}$ & s & $\mathbf{R}$ & ++ & ++ & +++ & +++ & $\mathrm{P}^{*}$ \\
\hline JAV253 & & & $\mathrm{i}$ & $\mathbf{s}$ & $\mathbf{s}$ & $\mathbf{R}$ & +++ & +++ & +++ & +++ & $\mathbf{N}$ \\
\hline JAV253-C3 & 12,700 & + & $\mathbf{r}$ & $\mathbf{s}$ & $\mathbf{s}$ & $\mathbf{R}$ & $+++(+)$ & +++ & ++++ & ++++ & $\mathbf{N}$ \\
\hline JAV352 & & & $\mathbf{s}$ & $\mathbf{s}$ & $\mathbf{s}$ & $\mathbf{P}$ & ++ & + & - & ++ & L \\
\hline JAV352-C3 & 310 & + & s & s & s & $\mathbf{P}$ & + & - & - & - & $\mathrm{P}^{*}$ \\
\hline JAV368 & & & i & i & s & $\mathbf{R}$ & - & - & - & - & L \\
\hline JAV368-C3 & 216 & - & $\mathbf{r}$ & $\mathbf{r}$ & $\mathbf{r}$ & W & - & - & - & - & $\mathbf{N}$ \\
\hline JAV399 & & & $\mathbf{s}$ & $\mathbf{s}$ & $\mathbf{s}$ & $\mathbf{R}$ & - & - & - & - & L \\
\hline JAV399-C3 & 128 & - & $\mathrm{i}$ & $\mathbf{s}$ & s & $\mathbf{R}$ & ++ & - & ++ & - & $\mathrm{P}^{*}$ \\
\hline $\mathrm{ACl}(\mathrm{WT})$ & 136 & & s & $\mathbf{s}$ & $\mathbf{s}$ & $\mathbf{R}$ & ++++ & ++++ & ++++ & ++++ & $\mathbf{N}$ \\
\hline pop6510 & & & $\mathrm{r}$ & $r$ & $\mathbf{r}$ & W & - & - & - & - & $\mathbf{N}$ \\
\hline AJC146 & & & $\mathbf{r}$ & $r$ & $\mathbf{s}$ & $\mathbf{R}$ & & & & & $\mathbf{N}$ \\
\hline AJC146-C3 & & - & $\mathrm{r}$ & $r$ & $\mathbf{r}$ & $\mathbf{R}$ & & & & & $\mathrm{N}$ \\
\hline AJC153 & & & $\mathrm{i}$ & $\mathbf{s}$ & $\mathrm{s}$ & $\mathbf{R}$ & & & & & $\mathbf{N}$ \\
\hline AJC153-C3 & 33,312 & + & $r$ & $\mathbf{s}$ & $\mathbf{s}$ & $\mathbf{R}$ & & & & & $\mathbf{N}$ \\
\hline AJC374 & & & $\mathrm{r}$ & $\mathrm{i}$ & s & $\mathbf{R}$ & & & & & $\mathbf{N}$ \\
\hline AJC374-C3 & 14,202 & + & $r$ & $\mathrm{i}$ & $\mathbf{s}$ & $\mathbf{R}$ & & & & & $\mathbf{P}$ \\
\hline
\end{tabular}

${ }^{a}$ Strains with plasmids encoding LamB proteins with a linker insertion are designated JAV (isolated in this study) or AJC (8), followed by a number indicating the position of the residue preceding the insert. The corresponding strain, in which the $\mathrm{C} 3$ epitope was inserted into the BamHI linker site, carries the same name followed by -C3. Strain pop6510(pAC1) with the plasmid encoding the wild-type LamB protein is abbreviated AC1(WT).

$b$ Efficiency of plating was determined by spot tests of different dilutions of phage stock on a lawn of bacteria on liquid minimal medium. s, Sensitive (efficiency of plating of 1); r, resistant (efficiency of plating of $<10^{-5}$ ); i, intermediate (efficiency of plating of $10^{-3}$ to $10^{-1}$ ).

${ }^{c}$ Color of colonies on McConkey dextrin plates $(0.5 \%)$. R, Red (dextrin-positive phenotype); W, white (dextrin-negative phenotype); P, pink (interpreted as an intermediate phenotype).

${ }^{d}$ ELISA on intact bacteria with four MAbs directed against cell surface-exposed determinants of LamB.,++++ Signal comparable to that for wild-type LamB; - , background value. Other symbols correspond to intermediate signals.

e Assayed at two temperatures $\left(30\right.$ and $37^{\circ} \mathrm{C}$ ) in liquid minimal medium with glucose as a carbon source supplemented with Casamino Acids and in the presence of ampicillin. The mutants showed comparable behaviors at both temperatures (data not shown). IPTG was added to exponentially growing cultures at OD 600 0.4 , and $\mathrm{OD}_{600}$ was recorded up to 1.5. N, No effect on growth rate of addition of IPTG; P, growth reached a plateau one generation after the addition of IPTG $\left(\mathrm{OD}_{600}=0.8\right) ; \mathrm{P}^{*}$, growth reached $\mathrm{OD}_{600}=0.7$ to 0.8 and then decreased slightly to 0.6 to $0.7 ; \mathrm{L}$, growth was strongly affected and extensive cell lysis occurred after IPTG addition $\left(\mathrm{OD}_{600}=0.4\right.$ to 0.5$)$.

$f$ Detection with anti-C3 MAb by using RIA on intact bacteria treated with the anti-C3 MAb. Values indicate counts per minute recorded from ${ }^{125}$ I-protein A.

$\boldsymbol{g}$ Detection with anti-C3 MAb by using immunoprecipitation of bacterial extracts (Fig. 3 ).

\section{DISCUSSION}

We have identified eight new permissive sites in the LamB protein by using an improved version of a previously described two-step genetic technique $(4,8)$. In the first step, we simply screened mutant proteins for activity (phage receptor), while in the previous method we had analyzed and sequenced all of the linker insertions producing stable immunodetectable mutant proteins. In the second step, we cloned a mixture of three oligonucleotides encoding the $\mathrm{C} 3$ epitope in different reading frames into the newly created BamHI sites and used an immunoscreen to detect the inserts in the correct frame. This allowed us to sequence only the clones expressing the $\mathrm{C} 3$ epitope. The new procedure was quite efficient, since of 10 potential permissive sites detected in the first step, 8 proved to be permissive. This procedure could, in principle, be used for any protein for which an activity test is available and which can be expressed in $E$. coli (see below).
LamB topology with a reporter epitope. Our screening procedure ensured that the $\mathrm{C} 3$ epitope could be detected within the denatured LamB-C3 monomers by the C3 MAb. To obtain information of the topology of the hybrid proteins, we examined whether the $\mathrm{C} 3$ epitope could be detected in vivo on intact cells or in vitro on the active forms of LamB (trimers and aggregates of trimers).

The hybrid protein with the $\mathrm{C} 3$ insertion at site 253 led to detection of the $\mathrm{C} 3$ epitope at the bacterial surface. This constitutes the first direct argument for the outside position of the corresponding LamB loop as proposed by our folding model on the sole basis of mutations to phage resistance (10). It is worth mentioning that by all criteria used here, the $C 3$ insertion at site 253 caused no detectable changes in the organization or location of the hybrid protein. The only phenotypic change detected (resistance to $\lambda \mathrm{h}+$ ) can be attributed to a local effect on the phage receptor area similar to that of missense mutations in the same loop. 
The LamBJAV253-C3 hybrid protein could form in vitro detectable trimers or higher multimers. This was also true for C3 inserts at five other positions. At four of them (sites $183,219,236$, and 352) but not at the fifth (site 399), the C3 epitope could be detected at the surface of the extracted oligomeric hybrid proteins. This exception could be due either to the fact that the $\mathrm{C} 3$ epitope is exposed but constrained or to the fact that it is not exposed. Because we found that the LamBJAV399-C3 protein was cleaved by trypsin at only one site at or near the insert, we favor the idea that it could be exposed but constrained (data not shown). Demonstration of this point would require sequencing of the cleavage site.

If we assume, as is suggested by the properties of the LamBJAV253-C3 protein, that the conformations of the hybrid proteins are similar in vivo and in vitro, the fact that sites 183 and 352 did not lead to exposure of the C3 epitope at the cell surface is in agreement with our model, which predicts exposure to the periplasm. In contrast, the region of site 236 was predicted to be at or near the cell surface. The absence of detection of $\mathrm{C} 3$ in vivo at this site, where it is detected in vitro, suggests to us that the epitope is not accessible to the antibody because it is at least partially buried in vivo. Since the region between sites 236 and 219 is predicted as a transmembranous beta-strand of 13 residues (larger than a membrane-spanning segment), this interpretation would imply that the C3 epitope at site 219 is exposed to the periplasm. We have therefore slightly shifted the position of the region from 219 to 236 in the model to make it compatible with this interpretation (Fig. 4). However, at this stage other interpretations are possible, such as conformational constraints exerted in vivo (but not in vitro) on $\mathrm{C} 3$ at site 236 and exposure of $\mathrm{C} 3$ at site 219 on the side of the extracted trimer.

For the $\mathrm{C} 3$ insertions at the four remaining sites $(68,123$, 168 , and 368), no trimers were detected in vitro. Two were the nonpermissive sites for which the proteins were degraded in extracts (sites 168 and 368); for the two others (sites 68 and 123), we concluded that formation of the trimers was partially defective. Thus, insertion of $\mathrm{C} 3$ resulted at these sites in perturbations in the structure or maturation of the LamB-C3 proteins, which prevented us from drawing conclusions as to the positions of the insertion sites with respect to the rest of the protein.

Functional changes. The topological conclusions drawn here rely on the hypothesis that the effects of the genetic changes were essentially local. It was important to examine whether this hypothesis was fulfilled. In absence of direct structural data, we used several criteria.

The first criterion was the conservation of in vitro biological activities (phage growth and maltodextrin fermentation). By definition, $\mathrm{C} 3$ insertion at permissive sites preserved at least one of the two functions and therefore resulted in silent or specific mutations. Genetic analysis of LamB functions had revealed previously that the first third of the protein (to residue 146) was devoted mainly to the maltodextrin channel and binding site, while the phage receptor area was found mainly in the last two-thirds of the protein $(10,21)$. In agreement with this view, the $\mathrm{C} 3$ insertions at permissive sites abolishing maltodextrin fermentation occurred in the first third of the protein (sites 68 and 123). Another insertion into the permissive site 352 partially affected maltodextrin fermentation. These results are in agreement with the findings that point or linker insertion mutations at residues 74 to 82 (near site 68), at residues 118 to 121 (near site 123), and at residues 360 to 362 (near 352) affect starch binding and maltodextrin transport (21). Similarly, C3 insertion affecting specifically phage adsorption occurred at sites 236,253 , and 399 , in the last two-thirds of the protein. These sites belong to two regions proposed on the basis of the properties of point mutants to be part of the primary site for the adsorption of phage $\lambda(10,19)$.

Thus, the genetic modifications due to the $\mathrm{C} 3$ insertion at permissive sites either were silent (sites 183 and 219) or resulted in activity changes comparable to those due to point or linker insertion mutations in the same regions. This view agrees with the hypothesis that the insertions at the permissive sites provoke no or only limited long-range effects.

The C3 insertion at site 399 deserves a special comment. The linker insertion occurred together with a deletion of 10 residues extending from residues 399 to 409 . These changes preserved at least partially infectivity by phage $\lambda$ and fully by its host range mutants. This finding is surprising, since we showed previously that a missense mutation at residue 401 (a Gly-to-Asp substitution) prevented infection by phage $\lambda$ (although not at the first reversible step but at a later irreversible step) (10). Since Gly-401 is included in the deletion carried by LamBJAV399-C3, either this residue is not strictly needed for infection (the effect of the Gly-401 mutation would be indirect) or the linker insertion can supply the function of the wild-type sequence. It is worth mentioning also that the deletion occurring at site 399 includes the sequence Arg-Gly-Asp, which corresponds to the active site of fibronectin and was proposed to be responsible of the aggregation of mammalian cells due to LamB (36). It will be interesting to examine whether the deletion affects this process.

Conformations and locations of the hybrid proteins. The results obtained with four MAbs that specifically recognize cell surface-exposed conformational determinants located after residue 330 of LamB confirmed that upon insertion of the $\mathrm{C} 3$ epitope into permissive sites, the main deformations of the hybrid protein were limited to the area of the insert. In agreement with the idea that this assay reflects the degree of deformation of the modified proteins, we found also that the LamB mutant proteins due to the BamHI linker insertion were generally recognized by more of the MAb clones than were the corresponding hybrid proteins (Table 2). The only exception was site 399 , where the linker insertion mutant was detected by none of the MAbs while the hybrid protein was recognized by two of them; because this site is within the region of the critical antigenic determinants, this result is probably due to local conformational changes. Also, the only linker insertion mutant LamB proteins that were not detected on intact cells by all four MAbs corresponded to the three more distal inserts (sites 352, 368, and 399), which were also the sites less well detected by immunoblot with the anti-LamB monomer serum (Fig. 2B). This result agrees with the idea that major LamB epitopes were directly affected by the insertions in this region.

The two other criteria used for monitoring deformations in the hybrid proteins consisted in examining sensitivity to trypsin and toxicity upon overproduction.

Evaluations of deformation of the proteins on the basis of the trypsin sensitivity assays were in agreement with those obtained from assays of the MAbs. They also supported the view that deformations were more important for the LamB-C3 hybrid proteins than for the linker insertion mutants.

We previously provided evidence that at least in some cases, toxicity was due to improper insertion of the mutated 

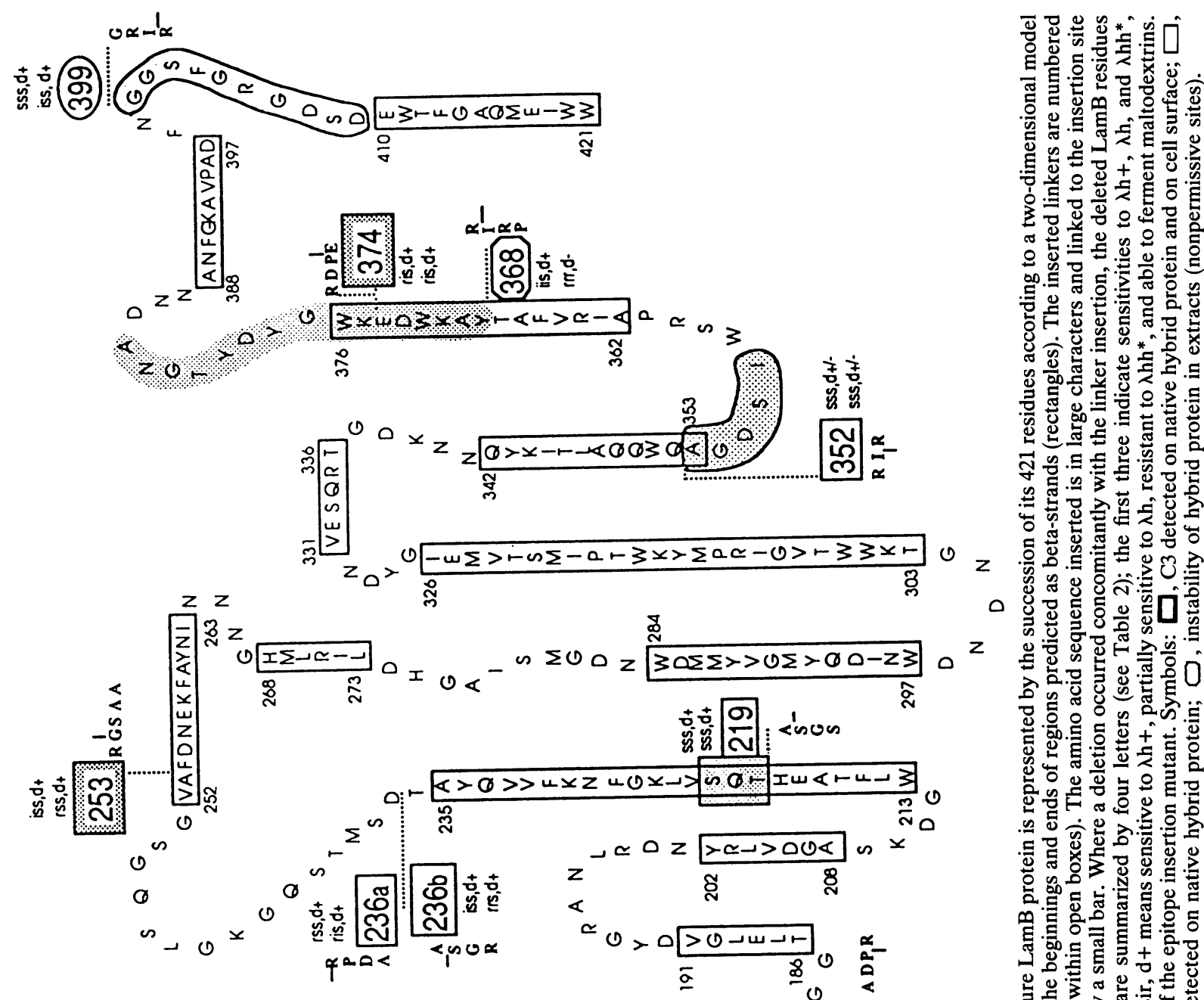

\section{0}
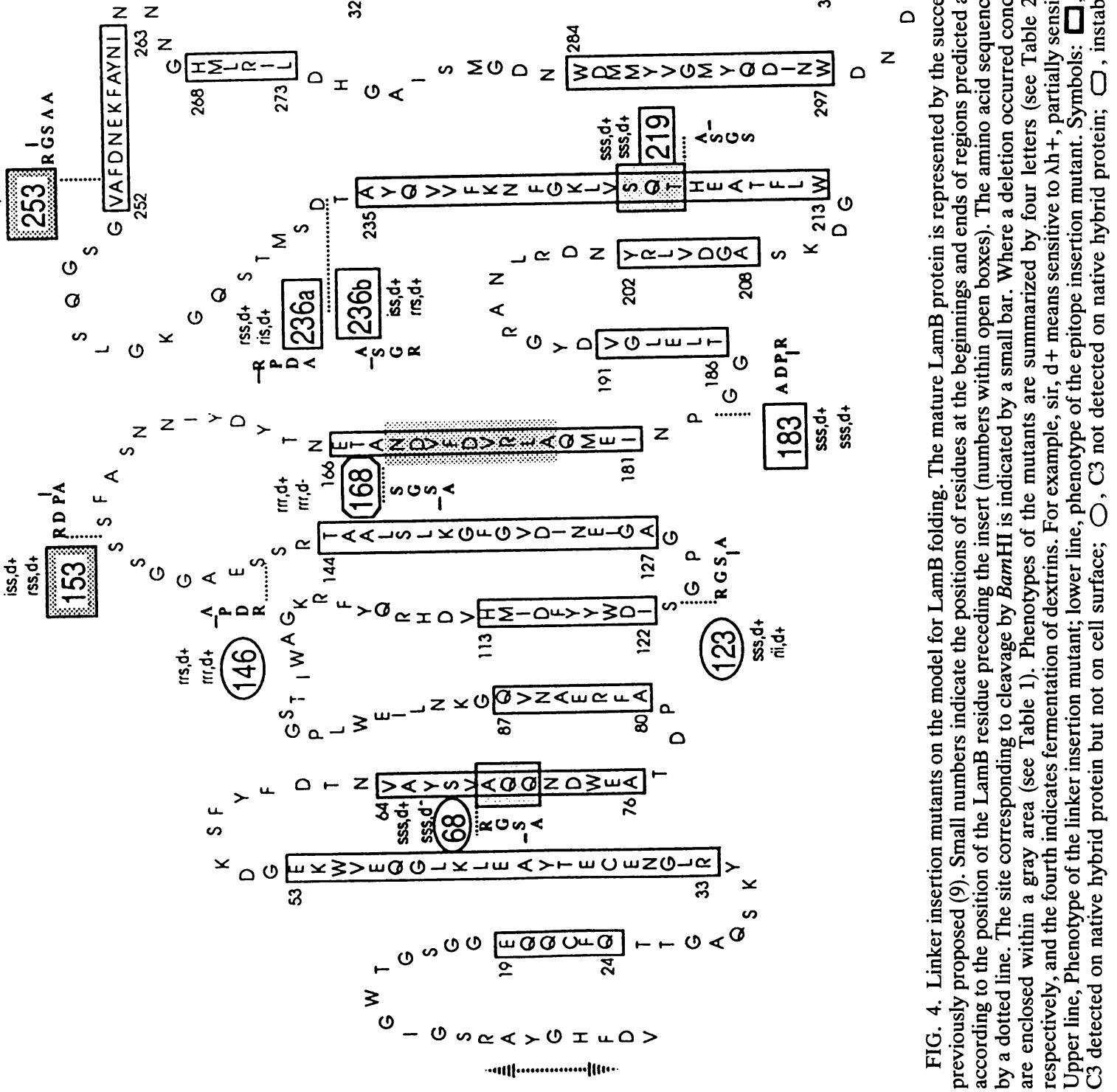
protein in the outer membrane, overloading of the outer membrane with abnormal LamB protein, or simply overproduction of the wild-type LamB protein (3). It is also known that some modified LamB proteins may be toxic because they affect the export machinery (for a review, see reference 42). Thus, toxicity indicates various abnormalities in the level of expression, export, maturation, membrane insertion, or folding of the protein. Toxicity proved a sensitive assay for revealing abnormalities, since only one linker insertion mutant and four $\mathrm{C} 3$ insertions were not toxic. The most clear-cut cases were the linker and C3 epitope insertions at site 253. The proteins were nontoxic and had retained most of their activities, showing that the biogenesis and final structures of the proteins were hardly affected. In contrast, the three other nontoxic cases were the hybrid proteins the most affected in their activities. Two corresponded to the nonpermissive sites (168 and 368) where all activities were abolished, and the other corresponded to site 123 , which was the permissive site where the $C 3$ insertion had the most severe effects on activities (maltodextrin fermentation was abolished, and only residual phage receptor activity was present). In these three cases, the absence of toxicity upon induction is probably due to deficiency in the integration into the outer membrane. This interpretation is supported by the fact that the three corresponding linker insertion mutants were toxic, suggesting that their less extensive modifications still allowed integration of an abnormal protein into the outer membrane.

Permissive sites and folding of LamB. Permissive sites were defined as regions of the protein that accept the insertion of a foreign sequence without major perturbation in the in vivo functions of the protein. These sites are expected to be found in regions that are nonessential for the proper folding, stability, or targeting of the protein. The conditions for folding require that such regions not be tightly organized and be rather flexible in sequence and in conformation. In most cases, such regions should occur at the surface of the protein in nonstructured segments. The conditions for targeting and stability are more difficult to express, since little is known about the modifications that affect them, especially in the case of a membrane protein. This is why a genetic approach leading to the experimental detection of permissive sites is especially useful in the case of an exported membrane protein such as LamB.

Six of the eight permissive sites detected in this study are located in regions predicted to be extramembranous loops of the protein. Such regions are indeed expected to be generally flexible. The two exceptions (sites 68 and 219) are located in predicted beta-strand transmembranous segments. Site 219 is shown in this report to be on the surface of the native protein. We propose the hypothesis that the region of site 219 could be extramembranous and face the periplasm. Site 68 is located in a region where the model relies entirely on predictions, and its location with respect to the membrane has yet to be demonstrated. As expected, the two nonpermissive sites in LamB (168 and 368) are located in regions predicted to be transmembranous. At these two sites, insertion of the BamHI linker had occurred together with fairly extensive deletions (Table 1A). This finding suggests that the corresponding regions of LamB may have a rather tight organization such that replacements or deletions but not net insertions are tolerated.

We had previously determined three permissive sites in LamB, after residues 146,153 , and 374 . They were all located in regions predicted to be extramembranous loops. The C3 epitope could be detected at the cell surface at sites
153 and 374 , while at site 146 the epitope was not detected either on the isolated trimers or on the bacteria. Thus, of 11 permissive sites found in LamB, 7 were found to lead to expression of the $\mathrm{C} 3$ epitope at the surface of the hybrid protein, and 3 of them resulted in detection at the cell surface. Site 153 was shown to accept insertions of up to about 60 residues and of a wide variety of sequences without loss of LamB activities in vivo. The degree of permissivity of other sites has not yet been evaluated.

Foreign peptides have been expressed in a number of other proteins without abolishing all of their activities or their locations (see, for example, references 1 and 34). In the case of alkaline phosphatase, for which the structure has been determined, the permissive sites, where most of the enzyme activity was conserved, were all located in loops located at the protein surface on the X-ray model (16). These data are in agreement with our results.

Permissive sites and vectors. In addition to providing topological information, insertions of foreign sequences in permissive sites of proteins provide information on the functional organization of the recipient protein: the genetic modifications may be correlated with modifications (or absence of modifications) in the biological properties of the protein. Conversely, the biological properties of the recipient protein may most often lead to hybrid proteins that confer interesting properties to the inserted sequence. We have shown that intact bacteria expressing a viral sequence within an exposed loop of LamB could elicit an antibody response against the corresponding virus or could be used as a simple diagnostic reagent (12).

The genetic method for detecting permissive sites can be generalized to other proteins, and depending on the properties of the recipient protein, different applications can be considered. We have started to use this method with two other proteins belonging to the maltose transport system: MalE, a periplasmic binding protein $(15,29 a)$, and $M a l G$, an integral membrane protein (13a). Because the MalE protein can be conveniently purified by affinity chromatography in mild conditions, this provides a simple way to prepare peptides or even large polypeptides (43).

By using permissive sites, the same epitope can be expressed at different sites in the same protein or in different proteins; these constructions open a genetic approach to the role of context in the immunogenicity of an epitope and may have implications for vaccine design $(25,44)$. Finally, derivatives of the MalE protein with the $\mathrm{C} 3$ epitope inserted within a permissive site have recently been crystallized, opening the way to the determination of the structure of this epitope in a new context (38).

\section{ACKNOWLEDGMENTS}

We thank Annie Molla for help with the ELISA with anti-LamB MAb, D. O. Callaghan for correcting the English of the manuscript, and Radu Crainic for providing anti-C3 MAb.

This work was supported by grants from the Association pour le Développement de la Recherche sur le Cancer, the Ligue Nationale contre le Cancer, the Fondation pour la Recherche Médicale, and World Health Organization (Transdisease Vaccinology Programme).

\section{REFERENCES}

1. Agterberg, M., H. Adriaanse, and J. Tommassen. 1987. Use of outer-membrane protein PhoE as a carrier for the transport of a foreign antigenic determinant to the cell surface of Escherichia coli K12. Gene 59:145-150.

2. Bartlett, J. A. 1986. Sequencing of supercoiled plasmid DNA. Biotechniques 4:208-210. 
3. Bouges-Bocquet, B., H. Villaroya, and M. Hofnung. 1984. Linker mutagenesis in the gene of an outer-membrane protein of $E$. coli: LamB. J. Cell. Biochem. 24:217-228.

4. Boulain, J. C., A. Charbit, and M. Hofnung. 1986. Mutagenesis by random linker insertion into the $\operatorname{lamB}$ gene of $E$. coli K12. Mol. Gen. Genet. 205:339-348.

5. Braun-Breton, C. 1984. Screening for $\operatorname{lamB}$ missense mutations altering all the activities of the lambda receptor in Escherichia coli K12. Ann. Microbiol. (Paris) 135A:181-190.

6. Braun-Breton, C., and M. Hofnung. 1981. In vivo and in vitro functional alterations of the bacteriophage lambda receptor in lamB missense mutants of Escherichia coli $\mathrm{K}-12$. J. Bacteriol. 148:845-852.

7. Broome-Smith, J., and B. Spratt. 1986. A vector for the construction of translational fusions to TEM- $\beta$ lactamase and the analysis of protein export signals and membrane protein topology. Gene 49:341-349.

8. Charbit, A., J.-C. Boulain, A. Ryter, and M. Hofnung. 1986. Probing the topology of a bacterial membrane protein by genetic insertion of a foreign epitope: expression at the cell surface. EMBO J. 5:3029-3037.

9. Charbit, A., J.-M. Clement, and M. Hofnung. 1984. Further sequence analysis of the phage lambda receptor site. Possible implications for the organization of the LamB protein in $E$. coli K12. J. Mol. Biol. 175:395-401.

10. Charbit, A., K. Gehring, H. Nikaido, T. Ferenci, and $M$. Hofnung. 1988. Maltose transport and starch binding in phage resistant point mutants of maltoporin functional and topological implications, J. Mol. Biol. 201:487-496.

11. Charbit, A., and M. Hofnung. 1985. Isolation of different bacteriophages using the LamB protein for adsorption on Escherichia coli K-12. J. Virol. 53:667-671.

12. Charbit, A., A. Molla, J. Ronco, J. M. Clément, V. Favier, E. M. Bahraoui, L. Montagnier, A. Leguern, and M. Hofnung. 1990. Immunogenicity and antigenicity of conserved peptides from the envelope of HIV1 expressed at the surface of recombinant bacteria. AIDS 4:545-551.

13. Clement, J.-M., and M. Hofnung. 1981. Gene sequence of the lambda receptor, an outer-membrane protein of $E$. coli $\mathrm{K} 12$. Cell 27:507-514.

13a.Dassa, E. Unpublished data.

14. Desaymard, C., M. Débarbouillé, M. Jolit, and M. Schwartz. 1986. Mutations affecting antigenic determinants on an outermembrane protein of Escherichia coli. EMBO J. 5:13831388.

15. Duplay, P., S. Szmelcman, H. Bedouelle, and M. Hofnung. 1987. Silent and functional changes in the periplasmic maltose binding protein of Escherichia coli K12. I. Transport of maltose. J. Mol. Biol. 194:663-673.

16. Freimuth, P. I., J. W. Taylor, and E. T. Kaiser. 1990. Introduction of guest peptides into Escherichia coli alkaline phosphatase. J. Biol. Chem. 265:896-901.

17. Gabay, J., S. Benson, and M. Schwartz. 1983. Genetic mapping of antigenic determinants on a membrane protein. J. Biol. Chem. 258:2410-2414.

18. Gabay, J., and K. Yasunaka. 1980. Interaction of the LamB protein with the peptidoglycan layer in Escherichia coli K-12. Eur. J. Biochem. 104:13-18.

19. Gehring, K., A. Charbit, E. Brissaud, and M. Hofnung. 1987. Bacteriophage lambda receptor site on the Escherichia coli K-12 LamB protein. J. Bacteriol. 169:2103-2106.

20. Hefiron, F., M. So, and B. J. McCarthy. 1978. In vitro mutagenesis of a circular DNA molecule by using synthetic restriction sites. Proc. Natl. Acad. Sci. USA 75:6012-6016.

21. Heine, H. G., G. Francis, K.-S. Lee, and T. Ferenci. 1988. Genetic analysis of sequences in maltoporin that contribute to binding domains and pore structure. J. Bacteriol. 170:1730 1738.

22. Hofnung, M., H. Bedouelle, J.-C. Boulain, J.-M. Clément, A. Charbit, P. Duplay, K. Gehring, P. Martineau, and W. Saurin. 1988. Genetic approaches to the study and the use of proteins: random point mutations and random linker insertions. Bull. Inst. Pasteur 86:95-101.
23. Horaud, F., R. Crainic, S. Van der Werf, B. Blondel, C. Wychowski, O. Akacem, P. Bruneau, P. Couillin, O. Siffert, and M. Girard. 1987. Identification and characterization of a continuous neutralization epitope (C3) present on type I poliovirus Prog. Med. Virol. 34:129-155.

24. Lathe, R., M. P. Kieny, S. Skory, and J. P. Lecocq. 1984. Laboratory methods linker tailing: unphosphorylated linker oligonucleotides for joining DNA termini. DNA 3:173-182.

25. Leclerc, C., P. Martineau, S. Van der Werf, E. Deriaud, P. Duplay, and M. Hofnung. 1990. Induction of virus-neutralizing antibodies by bacteria expressing the $\mathrm{C} 3$ poliovirus epitope in the periplasm. J. Immunol. 144:3174-3182.

26. Maniatis, T., E. F. Fritsch, and J. Sambrook. 1982. Molecular cloning: a laboratory manual. Cold Spring Harbor Laboratory, Cold Spring Harbor, N.Y.

27. Manoil, C. 1990 . Analysis of protein localization by use of gene fusions with complementary properties. J. Bacteriol. 172:10351042.

28. Manoil, C., and J. Beckwith. 1986. A genetic approach to analyzing membrane protein topology. Science 233:14031408.

29. Manoil, C., J. J. Mekalanos, and J. Beckwith. 1990. Alkaline phosphatase fusions: sensors of subcellular location. J. Bacteriol. 172:515-518.

29a.Martineau, P., J. G. Guillet, and M. Hofnung. Unpublished data.

30. Molla, A., A. Charbit, A. Le Guern, A. Ryter, and M. Hofnung. 1989. Antibodies against synthetic peptides and the topology of LamB, an outer-membrane protein from Escherichia coli K12. Biochemistry 28:8234-8241.

31. Murphy, C. K., V. I. Kalve, and P. E. Klebba. 1990. Surface topology of the Escherichia coli K-12 ferric enterobactin receptor. J. Bacteriol. 172:2736-2746.

32. Nakae, T., and J. N. Ishii. 1982. Molecular weight and subunit structure of LamB proteins. Ann. Inst. Pasteur Microbiol. 133A:21-25.

33. Neuhaus, J. M. 1982 . The receptor protein of phage lambda: purification, characterization and preliminary electrical studies in planar lipid bilayers. Ann. Microbiol. (Paris) 133A:27-32.

34. Newton, S. M., C. O. Jacob, and B. A. D. Stocker. 1989. Immune response to cholera toxin epitope inserted in Salmonella flagellin. Science 244:70.

35. Nikaido, H., and M. Vaara. 1985. Molecular basis of bacterial outer-membrane permeability. Microbiol. Rev. 49:1-32.

36. Pierschbacher, M. D., and E. Ruoslahti. 1984. The cell attachment activity of fibronectin can be duplicated by small synthetic fragments of the molecule. Nature (London) 309:30-34.

37. Reid, J., H. Fung, K. Gehring, P. E. Klebba, and H. Nikaido. 1988. Targeting of porin to the outer-membrane of Escherichia coli. J. Biol. Chem. 263:7753-7759.

38. Rodseth, L. E., P. Martineau, P. Duplay, M. Hofnung, and F. A. Quiocho. 1990. Crystallization of genetically engineered active maltose-binding proteins, including an immunogenic viral epitope insertion. J. Mol. Biol. 213:607-611.

39. Ronco, J., A. Charbit, and M. Hofnung. 1988. Creation of targets for proteolytic cleavage in the LamB protein of $E$. coli $\mathrm{K} 12$ by genetic insertion of foreign sequences. Biochimie 72 : 183-189.

40. Schenkman, S., A. Tusgita, M. Schwartz, and J. P. Rosenbush. 1984. Topology of phage lambda receptor protein. Mapping targets of proteolytic cleavage in relation to binding sites for phages or monoclonal antibodies. J. Biol. Chem. 259:75707576.

41. Sen, K., and H. Nikaido. 1990 . In vitro trimerization of OmpF porin secreted by spheroplasts of Escherichia coli. Proc. Natl. Acad. Sci. USA 87:743-747.

42. Silhavy, T. J., S. A. Benson, and S. D. Emr. 1983. Mechanisms of protein localization. Microbiol. Rev. 47:313-344.

43. Szmelcman, S., J. M. Clément, M. Jehanno, O. Schwartz, L. Montagnier, and M. Hofnung. 1990. Export and one-step purification from Escherichia coli of a MalE-CD4 hybrid protein that neutralizes HIV in vitro. J. AIDS 3:859-872.

44. van der Werf, S., A. Charbit, C. Leclerc, V. Mimic, J. Ronco, M. 
Girard, and M. Hofnung. 1990. Critical role of neighbouring sequences on the immunogenicity of the $\mathrm{C} 3$ poliovirus neutralization epitope expressed at the surface of recombinant bacteria. Vaccine 8:269-277.

45. van der Werf, S., C. Wychowski, P. Bruneau, B. Blondel, R. Crainic, F. Horodniceanu, and M. Girard. 1983. Localization of a poliovirus neutralization epitope in viral capsid polypeptide VP1. Proc. Natl. Acad. Sci. USA 80:5080-5084.

46. Vos-Sheperkeuter, G. H., and B. Witholt. 1984. Assembly pathway of newly synthesized LamB protein, an outer-membrane protein of Escherichia coli K12. J. Mol. Biol. 175:511.

47. Werts, C. Unpublished data. 